\title{
Homologous and Heterologous Expression and Maturation Processing of Extracellular Glutamyl Endopeptidase of Staphylococcus epidermidis
}

Yuko Ohara-Nemoto ${ }^{1, *}$, Toshio Ono ${ }^{1}$, Yu Shimoyama ${ }^{2}$, Shigenobu Kimura ${ }^{2}$ and Takayuki K. Nemoto ${ }^{1}$

${ }^{1}$ Department of Oral Molecular Biology, Course of Medical and Dental Sciences, Nagasaki University Graduate School of Biomedical Sciences, 1-7-1 Sakamoto, Nagasaki 852-8588, Japan

${ }^{2}$ Department of Oral Microbiology, Iwate Medical University School of Dentistry, 1-3-27 Chuodori, Morioka 020-8505, Japan

*Corresponding author. Department of Oral Molecular Biology, Course of Medical and Dental Sciences, Nagasaki University Graduate School of Biomedical Sciences, 1-7-1 Sakamoto, Nagasaki 852-8588, Japan. Phone: +81 95819 7643; fax: +81 958197642. e-mail: ynemoto@nagasaki-u.ac.jp

Running title: Maturation processing of GluSE 


\section{Abstract}

The extracellular serine endopeptidase GluSE (EC 3.4.21.19) produced by Staphylococcus epidermidis degrades fibronectin and type I collagen and is considered to be one of its virulence factors. In the present study, we investigated maturation processing of native GluSE and that heterologously expressed in Escherichia coli. In addition to the major 28-kDa mature protease, a small amount of proenzymes with molecular masses of 32, 30, and $29 \mathrm{kDa}$ were identified in the extracellular and cell wall-associated fractions from S. epidermidis. The pre $\left(\mathrm{M}_{1}-\mathrm{A}_{27}\right)$ - and pro $\left(\mathrm{K}_{28}-\mathrm{S}_{66}\right)$-segment regions were defined by $\mathrm{N}$-terminal analyses, and processing at the $\mathrm{E}_{32}-\mathrm{S}_{33}$ and $\mathrm{D}_{48}-\mathrm{I}_{49}$ bonds was responsible for production of the 30 - and $29-\mathrm{kDa}$ intermediates, respectively. The full-length form of GluSE, which was expressed as a C-terminal His ${ }_{6}$-tagged fusion protein in E. coli, was purified as three proenzymes equivalent to the native ones. These molecules possessing an entire or a part of pro-segment were proteolytically latent, and were converted to a mature $28-\mathrm{kDa}$ form in vitro by thermolysin cleavage at the $\mathrm{S}_{66}-\mathrm{V}_{67}$ bond. Mutation of the essential amino acid $\mathrm{S}_{235}$ suggested auto-proteolytic production of the 30- and 29-kDa intermediates. Furthermore, truncated pro-enzymes demonstrated that the pro-segment of GluSE not only functions as an inhibitor of the protease but also facilitates thermolysin processing. These findings could offer clues to the molecular mechanism involved with regulation of proteolytic activity of pathogenic proteases secreted from S. epidermidis.

Keywords: Staphylococcus epidermidis; prepro-segment; recombinant protein; signal sequence; thermolysin; V8 protease. 


\section{Introduction}

Staphylococcus epidermidis, previously regarded as a harmless commensal, has increasingly been recognized as one of the most important pathogens of nosocomial infections accompanied by the frequent use of the foreign materials, such as devices and intravascular catheters, in recent medical treatments (Fidalgo et al., 1990; Patrick, 1990; Huebner and Goldmann, 1999). The factors of the pathogenicity of this organism have not been fully identified. Genome-based comparison with Staphylococcus aureus revealed that toxin genes, besides $\delta$-haemolysin and $\beta$-haemolysin, are not found, while genes coding for adhesin and several enzymes, including protease, lipase, hyaluronidase, are found in S. epidermidis (Zhang et al., 2003; Gill et al., 2005). Among these enzymes, secretory proteases, especially those exhibiting elastolytic activities, are considered to be one of etiological factors (Varadi, 1968).

We (Sasaki et al., 1998; Ohara-Nemoto et al., 2002) and other groups (Moon et al., 2001; Dubin et al., 2001) characterized a major extracellular protease of S. epidermidis, designated GluSE, and cloned its structural gene, gseA (Dubin et al., 2001; Ohara-Nemoto et al., 2002). GluSE is a $28-\mathrm{kD}$ a serine protease with a dominant preference for Glu and a lesser preference for Asp at the P1 position. This protease efficiently degrades elastin, fibronectin, type I collagen, complement protein C5 and several other proteins. Further, gseA is commonly present in S. epidermidis strains isolated from both infected patients and healthy subjects, and the production of GluSE was also demonstrated in those clinical isolates (Ikeda et al., 2004). Those observations thus suggest an important biological role of GluSE, similar to the S. aureus ortholog, V8 protease (referred to GluV8, Drapeau et al., 1972), which contributes to in vivo growth and survival of the microorganism (Coulter et al., 1998; Rice et al., 2001).

GluSE belongs to the glutamyl endopeptidase I family [EC 3.4.21.19] (Stennicke and Breddam, 1998), which includes proteases from Bacillus licheniformis (Kakudo et al., 1992), Streptomyces griseus (Suzuki et al., 1994), and Streptomyces fradiae (Kitadokoro et al., 1993). Glutamyl endopeptidase of Enterococcus faecalis was recently cloned and characterized (Kawalec et al., 2005). Among the family members, the amino acid 
sequence of mature GluSE is most similar to that of GluV8 (59.1\%), while the prepro-segment has a limited similarity (23.5\%) (Ohara-Nemoto et al., 2002). GluSE consists of 282 amino acids, while GluV8 of S. aureus strain V8 consists of 336 including a unique C-terminal tail composed of a 12-fold repeat of tripeptide Pro-Asp/Asn-Asn (Carmona and Gray, 1987). The role of the repeat sequence remains unknown.

Proteases are generally synthesized as an inactive precursor, proenzyme or zymogen, which is converted to mature active enzyme generally through proteolysis at the peptide bond between the pro- and mature form. This activation pathway has been well characterized with trypsin-like serine proteases (Neurath and Walsh, 1976). As in majority of these proteases, maturation of GluV8 is achieved by restricted proteolysis of the proenzyme with a thermolysin-like neutral metalloprotease in S. aureus (Drapeau, 1978). The GluV8 activation process involves the proteolytic cascade of major extracellular pathogenic proteases of this microorganism, including aureolysin/Aur (metalloprotease), GluV8/SspA (serine protease), and SspB (cysteine protease) (Shaw et al., 2004). The activation cascade of exoproteases including GluSE remains to be elucidated in S. epidermidis.

Expression of recombinant GluSE in Escherichia coli would be useful to elucidate in detail the roles of the preprosegment and specific amino acid residues in the mature region that are involved in the enzymatic activity. However, the expression of the glutamyl endopeptidases has not succeeded except for one study to date (Yabuta et al., 1995). Because the study attached external peptides at the $\mathrm{N}$ - and $\mathrm{C}$-termini to the mature sequence of GluV8 to prevent auto-proteolysis, no information on the processing was deduced. Besides the E. coli expression system, the expression of a glutamyl endopeptidase-family protease from B. licheniformis was achieved by use of Bacillus subtilis as a host (Kakudo et al., 1992); and that of S. griseus, by Streptomyces lividans expression system (Suzuki et al., 1994). Hence, a convenient and efficient expression system of the glutamyl endopeptidase I in E. coli has not been established to date.

In the present study, we investigated maturation processing of GluSE expressed in $S$. epidermidis and that heterologously expressed in E. coli. The pre- and pro-segments of GluSE were defined as $\mathrm{M}_{1}-\mathrm{A}_{27}$ and $\mathrm{K}_{28}-\mathrm{S}_{66}$, respectively. Full length of GluSE was 
successfully expressed as soluble proforms in E. coli, which were converted to an active enzyme in vitro by thermolysin cleavage at the $\mathrm{S}_{66}-\mathrm{V}_{67}$ bond. We also demonstrated that the auto-proteolytic process occurred within the pro-segment at the $\mathrm{E}_{32}-\mathrm{S}_{33}$ and $\mathrm{D}_{48}-\mathrm{I}_{49}$ bonds and that the pro-segment was required for both suppression of the proteolytic activity and efficient processing by a processing enzyme. 


\section{Results}

\section{Processing of GluSE produced in S. epidermidis}

Extracellular proteins from S. epidermidis ATCC 14990 cultured using the dialysis membrane (DM) culture method were separated on two-dimensional (2D)-PAGE (Figure 1). Distinguished protein spots, which ranged in $\mathrm{p} I$ from 4 to 9 and in molecular masses from 20 to $50-\mathrm{kDa}$, were analyzed by MALDI-TOF MS spectrometry, to investigate maturation processing of GluSE. A $28-\mathrm{kDa}$ mature GluSE was recognized as the major protein constituent, in accord with the previous results of one-dimension SDS-PAGE of $S$. epidermidis S-19 (Sasaki et al., 1998) and ATCC 14990 (Ohara-Nemoto et al., 2002). Ecp, a $22-\mathrm{kDa}$ extracellular cysteine protease (Dubin et al., 2001), was also observed in the extracellular fraction of the DM culture, whereas aureolysin, a 32.7-kDa metalloprotease with estimated pI=4.3 (Teufel and Götz, 1993; Sabat et al., 2000), was not detected. In addition to the $28-\mathrm{kDa}$ mature enzyme, three spots at 32,30 , and $29 \mathrm{kDa}$ were identified to be GluSE (Figure 1). N-terminal sequences of the larger GluSE forms as well as the $28-\mathrm{kDa}$ mature form were determined and the results indicated that the $32-29-\mathrm{kDa}$ forms were proenzymes (Table 1). Assuming that processing occurred at the pro-segment region and not at the C-terminal end, the potential positions of these pro- and mature GluSEs based on the calculated molecular masses and pI were in good agreement with the spots observed in the 2D-PAGE experiment (Figure 1B). Therefore, the N-terminal processing primarily accounted for the mobility of the GluSE species in the 2D-PAGE assays.

In addition to the extracellular enzyme, cell wall-associated form of Ecp has been found (Oleksy et al., 2004). 2D-PAGE analysis was thus performed to examine whether pro- and mature forms of GluSE were present in the cell wall-associated fraction or not. No predominant spot in the $28-\mathrm{kDa}$ region was demonstrated with Coomassie Brilliant Blue (CBB) staining, however, immunoblotting revealed four forms of 32-, 30-, 29- and 28-kDa GluSE (Figure 2). The 32-kDa proform was dominant among them, and the N-terminal sequence of this spot could be determined to KTDTE, which was the same as that of the 32-kDa form from the extracellular fraction (Table 1). Taken together, we concluded that 
$\mathrm{M}_{1}-\mathrm{A}_{27}$ is a pre-segment, which contains a signal sequence, and that $\mathrm{K}_{28}-\mathrm{S}_{66}$ is a pro-segment. These results suggest that GluSE is secreted as the 32-kDa proenzyme, which is subsequently converted to the $29-$ and $30-\mathrm{kDa}$ intermediates and the $28-\mathrm{kDa}$ mature enzyme. As we reported previously (Sasaki et al., 1998; Ohara-Nemoto et al., 2002), the 28-kDa form was enzymatically active, whereas it remained unknown whether the $32-29-\mathrm{kDa}$ proenzymes possessed the enzymatic activity. To address this issue and further collect the information on the role of the prepro-segment, we expressed recombinant GluSE (rGluSE) in E. coli.

\section{Heterologous expression of GluSE in E. coli}

To minimize modification in the N-terminal prepro-segment, a pQE60 expression vector that attached an affinity $\mathrm{His}_{6}$-tag at the C-terminus was utilized for heterologous expression of GluSE. The only modification to the N-terminus was the insertion of GGS between $\mathrm{M}_{1}$ and $\mathrm{K}_{2}$. rGluSE was recovered in the soluble lysate and then purified by a one-step affinity chromatography. Approximately $18 \mathrm{mg}$ of rGluSE was obtained from 11 culture. The preparation contained two major forms with apparent molecular masses of 32 and $30 \mathrm{kDa}$ and a faint $29-\mathrm{kDa}$ form (Figure 3). The ratio of these forms appeared to vary in the preparations (data not shown), indicating that rGluSE was processed during the expression or purification step. In fact, purified rGluSE changed its composition after standing at $25^{\circ} \mathrm{C}$ for 1 week, as the $32-\mathrm{kDa}$ form was gradually decreased, the $30-\mathrm{kDa}$ form transiently increased, and finally, the 29-kDa form became accumulated (Figure 3).

$\mathrm{N}$-terminal sequencing of rGluSE revealed that the N-termini of the 32- and 29-kDa forms were $\mathrm{K}_{28}$ and $\mathrm{I}_{49}$, respectively, as same as those of the native proenzymes (Table 1). The 30-kDa form (Figure 3A, Day 0) was a mixture of two species starting at $\mathrm{S}_{33}$ or $\mathrm{S}_{37}$. Because these molecules were purified using the affinity chromatography, the C-terminal His-tag should be retained and their co-migration on SDS-PAGE seemed to due to the subtle difference in the molecular masses. Therefore, these rGluSEs were processed identically as the native GluSEs, except for one of the two $30-\mathrm{kDa}$ forms with $\mathrm{S}_{37}$ at the 
N-terminus. Production of the 30- and 29-kDa GluSEs strongly suggested auto-proteolytic cleavages at the $\mathrm{E}_{32}-\mathrm{S}_{33}$ and $\mathrm{D}_{48}-\mathrm{I}_{49}$ bonds, although the three rGluSEs showed only a trace or no hydrolyzing activity toward the Z-LLE-MAC peptide (Figure 3).

\section{In vitro processing of rGluSE}

Because the 29- and $30-\mathrm{kDa}$ intermediate forms showed no or trace of the glutamic acid-specific proteolytic activity, rGluSE might be either incorrectly folded or necessary to be precisely processed at the $\mathrm{S}_{66}-\mathrm{V}_{67}$ bond. It has been reported that GluV8 is processed and activated by aureolysin (Drapeau 1978; Shaw et al., 2004), which belongs to the thermolysin family of metalloproteases. Since a metalloprotease from S. epidermidis with the characteristics similar to aureolysin has been reported (Teufel and Götz, 1993; Sabat et al., 2000), we suspected that the maturation and activation of GluSE is also mediated by this metalloprotease. Accordingly, here we tested thermolysin for the in vitro processing of rGluSE (molar ratio 180 000:1 to 180:1). Truly, thermolysin treatment of 32-29-kDa rGluSEs produced a 28-kDa mature enzyme with an $\mathrm{N}$-terminus of $\mathrm{V}_{67}$ (Figure 4 and Table 1). Zymography confirmed that the 32-29-kDa rGluSEs were enzymatically latent and that the $28-\mathrm{kDa}$ entity solely exerted the caseinolytic activity (Figure 4B). Further, hydrolytic activity toward Z-LLE-MCA increased in concert with the appearance of the $28-\mathrm{kDa}$ form. The relative activity of the 28-kDa rGluSE was in accord with that of the native protease (data not shown). Therefore, rGluSE could be correctly folded and the proteolytic activity was gained by processing at the $\mathrm{S}_{66}-\mathrm{V}_{67}$ bond.

\section{Auto-proteolytic production of the 30- and 29-kDa rGluSEs}

rGluSE was incubated alone at a wide range of concentrations from 0.1 to $33.3 \mu \mathrm{M}$ at $37^{\circ} \mathrm{C}$ for $72 \mathrm{~h}$. As shown in Figure 5, the conversion appeared to be independent of the 
concentrations of GluSE, which might suggest that auto-processing occurred in an intramolecular manner. Secondly, we expressed a constitutively inactive form of rGluSE, of which an essential amino acid S235 was mutated to A (designated rGluSE S235A). The essential catalytic triad, $\mathrm{H}_{117}, \mathrm{D}_{159}$, and $\mathrm{S}_{235}$, common to serine proteases, was estimated from the deduced amino acid sequence (Ohara-Nemoto et al., 2002). Only the 32-kDa proform of rGluSE S235A was purified and the 30- and 29-kDa intermediates were not present in contrast to the wild-type rGluSE (Figure 5). This result clearly demonstrated that the intermediates were produced by auto-proteolysis. Following treatment with thermolysin, the $32-\mathrm{kDa}$ rGluSE S235A was converted to the $28-\mathrm{kDa}$ form with $\mathrm{V}_{67}$ at the N-terminus, while no proteolytic activity was detected. These results also confirmed an essential role of $\mathrm{S}_{235}$ in the proteolytic activity of GluSE. Furthermore, proper processing at $\mathrm{S}_{66}-\mathrm{V}_{67}$ suggested that the $\mathrm{S} 235 \mathrm{~A}$ mutation did not affect the three-dimensional structure, at least around the region of pro- and mature segments junction.

\section{Suppression of the proteolytic activity by truncated pro-segments}

In order to further investigate the role of the pro-segment in the suppression and folding of the mature peptide, a series of the N-terminal truncation forms of GluSE were expressed (Figure 6). Truncations starting from $\mathrm{K}_{28}, \mathrm{~S}_{33}$, and $\mathrm{I}_{49}$ mimicked the 32-, 30-, and 29-kDa native proGluSEs, respectively. rGluSEs from $\mathrm{I}_{56}$ further deleted, and possessed C-terminal 11 residues $\left(\mathrm{I}_{56}-\mathrm{S}_{66}\right)$ of the pro-segment. rGluSE from $\mathrm{S}_{66}$ (rGluSE Ser $_{66}$ ) was the molecule carrying the common exogenous tetra-peptide (MGGS) at the N terminus of mature GluSE starting from $\mathrm{V}_{67}$. Since the last $\mathrm{S}$ residue coincided with $\mathrm{S}_{66}$, the scissile bond was conserved in rGluSE Ser 66 . These recombinant molecules were purified as enzymatically inactive forms (Figure 6C). Using limited proteolysis with thermolysin (molar ratio 36:1), all of the molecules were converted to the $28-\mathrm{kDa}$ form and the proteolytic activities similar to that of rGluSE full were achieved, except for rGluSE $\operatorname{Ser}_{66}$

The thermolysin-treated rGluSE Ser $_{66}$ was a mixture with two species whose N-terminal 
sequences were $\mathrm{MGGS}_{66} \mathrm{~V}_{67}(80 \%)$ and $\mathrm{V}_{67} \mathrm{ILPN}_{71}$ (20\%). Accordingly, the lowest enzyme activity of GluSE Ser 66 was possibly due to inefficient cleavage at the $\mathrm{S}_{66}-\mathrm{V}_{67}$ bond. To confirm this idea, the dose dependence of thermolysin (from 10 800:1 to 3.6:1) was compared among rGluSE, rGluSE Ile 56 , and rGluSE Ser 66 . Figure 6D showed that rGluSE Ser 66 required one hundred-fold higher doses of thermolysin than those for rGluSE and GluSE Ile ${ }_{56}$ to form the mature protease. Taken together, it was concluded that the tetra-peptide, MGGS, completely suppressed the proteolytic activity but did not support the efficient cleavage at the $\mathrm{S}_{66}-\mathrm{V}_{67}$ bond by thermolysin, whereas the undeca-peptide of endogenous propeptide $\left(\mathrm{I}_{56}-\mathrm{S}_{66}\right)$ is sufficient for the two roles.

\section{Discussion}

We report here for the first time the existence of three forms of 32-, 30- and 29-kDa proGluSE found in the extracellular and cell wall-associated fractions of S. epidermidis. The N-terminal processing sites of GluSE are shown in Figure 7. The sequence $\mathrm{A}_{14} \mathrm{ALA}_{17}$ had been previously reported as a more probable signal sequence than $\mathrm{T}_{24} \mathrm{SYA}_{27}$ (Ohara-Nemoto et al., 2002) based on the A-X-A model (Perlman and Halvorson, 1983). However, the present results of the N-terminal analyses demonstrated that the peptide bond of $A_{27}-K_{28}$ was likely processed by a signal peptidase. Therefore, $M_{1}-A_{27}$ is the pre-segment and $\mathrm{K}_{28}-\mathrm{S}_{66}$ corresponds to the pro-segment of GluSE. GluSE was secreted as the $32-\mathrm{kDa}$ proenzyme through plasma membrane, and then processed to the $28-\mathrm{kDa}$ mature form. The observation that the $32-\mathrm{kDa}$ proGluSE was dominant and the $28-\mathrm{kDa}$ mature enzyme was scarcely recovered in the cell-wall fraction (Figure 2) may suggest the association of the pro-segment of GluSE with cell-wall components.

Maturation processing of GluSE was further assessed in detail with rGluSE, which was successfully expressed in E. coli as a soluble proform for the first time. The N-termini of recombinant 32-, 30- and 29-kDa GluSEs were identical to those of respective native forms, except for one of the two $30-\mathrm{kDa}$ forms with $\mathrm{S}_{37}$ as the $\mathrm{N}$-terminus. The protease that cleaved the $\mathrm{H}_{36}-\mathrm{S}_{37}$ bond was assumed to be an E. coli protease. The N-terminal 
sequence of native and recombinant proGluSEs suggests that the tetra-peptide of TSYA 27 was recognized by an $S$. epidermidis signal peptidase, which possessed substrate specificity similar to type I signal peptidase from E. coli (Fikes et al., 1990). With both homologous and heterologous expression, cleavage at $\mathrm{T}_{24} \mathrm{SYA}_{27} \mid \mathrm{K}_{28}$ bond would occur for production from the prepro- to pro-enzyme.

The N-terminal sequences of $30-$ and $29-\mathrm{kDa}$ proenzymes suggest auto-proteolytic processing at the $\mathrm{E}_{32}-\mathrm{S}_{33}$ and $\mathrm{D}_{48}-\mathrm{I}_{49}$ bonds. In fact, these intermediates were not found in the purified fraction of rGluSE S235A, a constitutive inactive form. The result in Figure 5 further suggested that the $30-$ and $29-\mathrm{kDa}$ intermediates may be produced by an intra-molecular auto-proteolysis. However, we could not completely exclude the possibility that the inter-molecular degradation is involved in the trimming of the pro-segment of GluSE. A further study should be needed to address this issue.

Thermolysin-like metalloprotease referred as aureolysin was demonstrated in $S$. epidermidis (Teufel and Götz, 1993), and its deduced amino acid sequence is $80 \%$ identical to S. aureus aureolysin (Sabat et al., 2000). Therefore, the cleavage for maturation at the $\mathrm{S}_{66}-\mathrm{V}_{67}$ bond could be catalyzed with aureolysin in vivo, the same as in the case of GluV8 (Drapeau 1978; Shaw et al., 2004; Nickerson et al., 2007). Because the substrate specificity of aureolysin is similar to that of thermolysin, we employed thermolysin as a processing enzyme for the in vitro processing of rGluSE. The study clearly demonstrated that the thermolysin/aureolysin-mediated mechanism faithfully operated the maturation of GluSE. The N-terminal truncates of proGluSE starting from $\mathrm{S}_{33}$ and $\mathrm{I}_{49}$ as well as $\mathrm{I}_{56}$ were processed at the $\mathrm{S}_{66}-\mathrm{V}_{67}$ bond by thermolysin and the proteolytic activity was fully demonstrated. Therefore, processing at $\mathrm{E}_{32}-\mathrm{S}_{33}$ and $\mathrm{D}_{48}-\mathrm{I}_{49}$ within the pro-segment seemed primarily not prerequisite for the cleavage between the $\mathrm{S}_{66}-\mathrm{V}_{67}$ bond.

We tried to measure the aureolysin activity in the extracellular fraction of S. epidermidis using rGluSE. However, there was no obvious conversion to the $28-\mathrm{kDa}$ mature form, but the 30- and 29-kDa intermediates were formed, under the same condition for thermolysin-treatment (T. K. Nemoto and Y. Ohara-Nemoto, unpublished observation). In consistent to this finding, a spot of aureolysin was not identified on 2D-PAGE (Figure 1A). 
Therefore, secretion of aureolysin may be limited or the enzyme mainly localizes at cellular compartments in strain ATCC 14990.

Heterologous expression of proteases is occasionally problematic, because uncontrolled activation of a recombinant protease could cause lethal damage against host cells. Success in the expression of recombinant proteases appears to be dependent on the compatibility between the repertoire of host cell proteases and a processing site of an expressed molecule. In the present expression system, the proforms of GluSE were purified from E. coli lysate. This result is likely to reflect the fact that E. coli does not possess a thermolysin ortholog, according to the GTOP database (http://spock.genes.nig.ac.jp/ genome/search.html). Therefore, it is suggested that the present expression method could be applicable to other proteases whose maturation processing is mediated by thermolysin-like proteases. Further, substitution of amino acids at the processing site, such as to thermolysin-specific peptides, may be useful for the stable expression of proteases.

The present expression system enabled us to analyze the biochemical characteristics of GluSE in detail with mutated sequences. For instance, the essential role of $\mathrm{S}_{235}$ was first proved by amino acid substitution and the suppression of the proteolytic activity by the pro-segment was clearly demonstrated in this study. Truncation mutation further revealed that the tetra-peptide $\left(\mathrm{MGGS}_{66}\right)$ suppresses the proteolytic activity. This result was in accordance with the previous report demonstrating that recombinant form of a GluV8 member that carries an additional GS di-peptide is devoid of activity (Popowicz et al., 2006). Therefore, these observations support the importance of $\mathrm{V}_{69}$ that was previously proposed by the structural analysis (Prasad et al., 2004): the $\alpha$-amino group of $\mathrm{V}_{69}$ of GluV8 specifically interacts with the carboxyl group of acidic amino acids of a substrate peptide. Accordingly, cleavage of the $\mathrm{S}_{66}-\mathrm{V}_{67}$ bond should be essential for activity acquisition of GluSE. Kawalec et al. (2005) recently reported that the processed form of the E. faecalis glutamyl endopeptidase $\mathrm{L}_{1}-\mathrm{SprE}$ was substantially more active than $\mathrm{S}_{-1}-\mathrm{L}_{1}-\mathrm{SprE}$. Thus, in addition to the suppression by the pro-segment due to possible steric hindrance, the N-terminal amino acids of glutamyl endopeptidases may be involved in substrate binding. 
It has been reported that pro-segments of thermolysin (O'Donohue and Beaumont 1996; Marie-Claire et al., 1999) and subtilisin (Subbian et al., 2005) function as intra-molecular chaperones as well as suppressors of the protease activities. The present study also demonstrated that the pro-segment $\mathrm{K}_{28}-\mathrm{S}_{66}$ prevents the proteolytic activity, and is further required for an efficient processing by thermolysin. However, the pro-segment of GluSE does not seem to have a role in the intra-molecular chaperone, because rGluSE Ser66 could acquire the full activity after thermolysin treatment (Figure 6D).

Is there any physiological meaning on the auto-proteolysis of GluSE occurring in the pro-segment? After we sent this manuscript, an interesting study on the processing of GluV8 endogenously expressed in S. aureus was reported (Nickerson et al., 2007). They reported the appearance of GluV8 carrying a short pro-segment, i.e., $\mathrm{H}_{66} \mathrm{AN}_{68}$ by an auto-proteolysis at the $\mathrm{E}_{65}-\mathrm{H}_{66}$ bond. Therefore, the auto-proteolysis seems to be the phenomenon common between GluSE and GluV8. Moreover, they proposed that the propeptide must be sequentially processed in the correct order, i.e., at first at the $\mathrm{E}_{65}-\mathrm{H}_{66}$ bond by GluV8 and finally at the $\mathrm{N}_{68}-\mathrm{V}_{69}$ bond by aureolysin. In the present study, the processing efficiency of rGluSE $\mathrm{I}_{56}$ by thermolysin was indistinguishable to that of GluSE full harboring pro-segment thoroughly (Figure 6D). Hence, their model will be carefully examined on GluSE in future studies. The recombinant form of GluSE should be useful to address this issue.

\section{Materials and methods}

\section{Bacterial strain and culture conditions}

S. epidermidis ATCC 14990 was obtained from the American Type Culture Collection (Rockvill, MD, USA). Following an overnight culture in Bacto Todd Hewitt broth (THB) (Becton, Dickinson and Company, Sparks, MD, USA), $10 \mu 1$ was inoculated on a THB agar plate $(\phi=9 \mathrm{~cm})$ seated with a sterilized dialysis membrane (cut off 6000$)$ (the DM method) as described previously (Ohara-Nemoto et al., 2002). Cultures were carried out at 
$37^{\circ} \mathrm{C}$ under aerobic conditions.

\section{Preparation of extracellular and cell wall-associated fractions of $S$. epidermidis}

Bacteria grown on agar plates were suspended with THB ( $3 \mathrm{ml} / \mathrm{plate})$. The suspension was centrifuged at $6000 \times \mathrm{g}$ for $15 \mathrm{~min}$, obtained supernatant was passed through a membrane filter (pore size $=0.45 \mu \mathrm{m}$ ), and then mixed with ice-cold trichloroacetic acid (TCA) to a final concentration of $15 \%(\mathrm{w} / \mathrm{v})$. After $15 \mathrm{~min}$ of standing on ice, the precipitate was collected by centrifugation at $20000 \times \mathrm{g}$ for $20 \mathrm{~min}$, then rinsed with ice-cold acetone, dried, and used as an extracellular fraction. A cell wall-associated fraction was extracted from the cell pellet, according to a previously reported method (Oleksy et al., 2004). Briefly, after washing with phosphate-buffered saline (PBS, pH7.4), cells were suspended with $8 \mathrm{M}$ urea in PBS in the presence of a complete protease-inhibitor cocktail (Roche Diagnostics, Mannheim, Germany) containing 1 mM EDTA and agitated. After $30 \mathrm{~min}$, the cell wall-associated fraction was separated by centrifugation at 20,000 x $g$ for 15 min at $4^{\circ} \mathrm{C}$ and then precipitated with $15 \%$ TCA. Extraction of the cell wall-associated fraction was also performed with either $0.1 \%$ TritonX100, $0.1 \%$ Nonidet $\mathrm{P} 40$, or $0.25 \mathrm{M} \mathrm{NaCl}$ in PBS. Similar results were obtained from the various procedures, thus representative results with $8 \mathrm{M}$ urea extraction are described in this report.

\section{D-PAGE}

Proteins $(100 \mu \mathrm{g})$ were dissolved in an $8 \mathrm{M}$-urea buffer [7.8 $\mathrm{M}$ urea, $2 \mathrm{M}$ thiourea, $1.9 \%$ Nonidet P40, $0.1 \mathrm{M}$ dithiothreitol, and $0.01 \%$ bromophenol blue] containing $0.5 \%$ pharmalyte (pH3-9) (GE Healthcare Bio-Science Co., Piscataway, NJ, USA) and a protease-inhibitor cocktail. Samples were electrically focused using an Immobiline DryStrip pH3-10 NL and IPGphore (GE Healthcare Bio-Science Co.) at $50 \mu$ A per strip for $3 \mathrm{~h}$ at $20^{\circ} \mathrm{C}$. For the second dimension, the strips were equilibrated in a $6 \mathrm{M}$ urea buffer (50 
mM Tris-HCl, pH 6.8, $6 \mathrm{M}$ urea, 3\% SDS, $50 \mathrm{mM}$ dithiothreitol, and $0.01 \%$ bromophenol blue) and separated on $12.5 \%(\mathrm{w} / \mathrm{v})$ polyacrylamide gels.

\section{Mass spectrometry}

Identification of proteins separated on 2D-PAGE was performed by mass spectrometry as reported previously (Shevchenko et al., 1996). Briefly, protein spots were excised and reduced. Following alkylation, in-gel digestion was performed with sequencing-grade trypsin (Promega, Madison, WI, USA) overnight at $37^{\circ} \mathrm{C}$. Peptides were extracted with $50 \%(\mathrm{v} / \mathrm{v})$ acetonitrile containing $5 \%(\mathrm{v} / \mathrm{v})$ trifluoroacetic acid, and then the extract was concentrated using a Speed Vac. Mass spectra were recorded on a Voyager DE-Pro MALDI-TOF mass spectrometer (Applied Biosystems, Branchburg, NJ, USA). Matrix-related ions and trypsin autolysis products were used for internal calibration. Peptide mass fingerprinting analysis was performed using ProteinProspector MS-fit available at http://prospector.ucsf.edu/prospector/4.0.8/html/msfit.htm.

\section{$\mathrm{N}$-terminal amino acid sequencing}

Native and recombinant proteins were separated on 2D-PAGE or 1-dimensional SDS-PAGE gels, then transferred to a polyvinylidene difluoride membrane (Bio-Rad, Richmond, CA, USA). The N-terminal amino acid sequences of the separated spots and bands were determined by Edman degradation and using a Procise cLC protein sequencer (PE Biosystems, Foster City, CA, USA), as described previously (Ohara-Nemoto et al., 2002).

\section{Immunoblotting and zymography}


Immunoblotting of GluSE was performed using polyclonal anti-GluSE serum, as described previously (Ohara-Nemoto et al., 2002). For zymography, samples were mixed with 3x SDS-sample buffer to give a final concentration of $25 \mathrm{mM}$ Tris-HCL ( $\mathrm{pH} 6.8$ ), 5\% glycerol, $1 \%$ SDS, $0.05 \%$ bromophenol blue, and 1\% 2-melcaptoethanol, then loaded without heating onto a $12.5 \%$ polyacrylamide gel containing $1 \mathrm{mg} / \mathrm{ml}$ of azocasein. Zymography was performed according to a method previously reported (Rice et al., 2001).

\section{Construction of expression vector of GluSE and in vitro mutagenesis}

GluSE was expressed in E. coli Y1090[pREP4] using a pQE60 (Qiagen Inc., Chatsworth, CA, USA). The C-terminal peptide derived from the plasmid was GSRSHHHHHH-COOH. The DNA fragment carrying the full-length GluSE was amplified with genomic DNA of $S$. epidermidis and a primer set (sense, 5'-TATGGATCCAAAAAGAGATTTTTATCTATATGTAC-3' and antisense, 5'-ATTGGATCCCTGAATATTTATATCAGGTATATTG-3') using of KOD plus DNA polymerase (Toyobo, Tokyo, Japan). BamHI sites introduced into the primers are underlined. A PCR product was cut with BamHI and then inserted into a BamHI site of pQE60, generating pQE60-GluSE. Similarly, the plasmids carrying truncated forms of GluSE encoding from $\mathrm{Lys}_{28}, \mathrm{Ser}_{33}, \mathrm{Ile}_{49}, \mathrm{Ile}_{56}$ and $\mathrm{Ser}_{66}$ to the C-terminal Gln 282 were constructed by PCR with the sets of appropriate sense primers and the antisense primer as described above.

Nucleotides (TCT) encoding $\operatorname{Ser}_{235}$ was substituted to those (GCT) encoding Ala by in vitro mutagenesis using PCR. The plasmid pQE60-GluSE was used as a template, and a sense (5'-GGATCTCCAGTATTTAATGGTAAA-3') and antisense PCR primer (5'-AGCGTTTCCACCTACAGTACTTAGGT-3') were used. The substitution introduced in the antisense primer is underlined. Following PCR, linear DNA was phosphorylated and self-ligated to produce the expression plasmid pQE60-GluSE Ser235Ala. Mutation was ascertained by DNA sequencing. 


\section{Expression and purification of recombinant proteins}

His-tagged recombinant proteins were expressed and purified as described previously (Nemoto et al., 2004). Briefly, an overnight culture of E. coli carrying a recombinant protein was diluted with $2 \mathrm{vol}$ of LB broth containing $50 \mu \mathrm{g} / \mathrm{ml}$ of ampicillin and $25 \mu \mathrm{g} / \mathrm{ml}$ of kanamycin, and further incubated at $30^{\circ} \mathrm{C}$ for $4 \mathrm{~h}$ in the presence of $0.2 \mathrm{mM}$ isopropyl- $\beta$-D-thiogalactopyranoside. Bacterial cells were harvested by centrifugation and lysed in lysis buffer (20 mM Tris- $\mathrm{HCl}, \mathrm{pH} 8.0,0.1 \mathrm{M} \mathrm{NaCl}$, and $10 \mathrm{mM}$ imidazole) containing $0.5 \mathrm{mg} / \mathrm{ml}$ of lysozyme by 3 cycles of freeze-thawing and ultrasonication. After centrifugation at $50000 \times \mathrm{g}$ at $4^{\circ} \mathrm{C}$ for $30 \mathrm{~min}$, the cell lysate was obtained and loaded onto a TALOM metal affinity resin (CLONTECH Lab. Inc., Palo Alto, CA, USA) column. Chromatography was performed according to the manufacturer's protocol, except that $10 \mathrm{mM}$ imidazole was included in the lysis/washing buffer. Bound rGluSE was eluted with $0.1 \mathrm{M}$ imidazole ( $\mathrm{pH} 8.0$ ) containing $10 \%(\mathrm{v} / \mathrm{v})$ glycerol.

\section{In vitro processing and measurement of protease activity}

rGluSE $(10 \mu \mathrm{g})$ was incubated with thermolysin (Sigma-Aldrich, St. Louis, MO, USA) at $37^{\circ} \mathrm{C}$ for $4 \mathrm{~h}$ in $0.1 \mathrm{ml}$ of reaction solution consisting of $10 \mathrm{mM}$ sodium borate, $\mathrm{pH} 8$, $0.005 \%$ Triton $\mathrm{X}_{100}$, and $2 \mathrm{mM} \mathrm{CaSO}_{4}$, unless otherwise stated. Thereafter, aliquots were subjected to SDS-PAGE and zymography, or assayed for proteolytic activity. Proteolytic activity was measured with GluSE ( 0.25 or $1 \mu \mathrm{g} /$ reaction $)$ using of $20 \mu \mathrm{M}$ of Z-LLG-MCA (Peptide Institute, Osaka, Japan) in $50 \mathrm{~mm}$ Tris- $\mathrm{HCl}$ (pH 8.0) containing $5 \mathrm{~mm}$ EDTA at $25^{\circ} \mathrm{C}$ for $1 \mathrm{~h}$ as described previously (Ohara-Nemoto et al., 2002). The fluorescence was measured with an excitation at $380 \mathrm{~nm}$ and emission at $460 \mathrm{~nm}$ with a Fluorescence Photometer F-4000 (Hitachi, Tokyo, Japan). EDTA was added to the reaction mixture for suppression of thermolysin activity (Fontana 1988). 


\section{Acknowledgements}

We thank Takeshi Kobayakawa for the excellent technical support. This work was supported in part by a grant from the program Grants-in-Aid for Scientific Research on Priority Areas from the Ministry of Education, Culture, Sports, Science, and Technology of Japan (to T. -K. N.). 


\section{References}

Carmona, C., and Gray, G.L. (1987). Nucleotide sequence of the serine protease gene of Staphylococcus aureus, strain V8. Nucleic Acids Res. 15, 6757.

Coulter, S.N., Schwan, W.R., Ng, E.Y.W., Langhorne, M.H., Ritchie, H.D., Westbrock-Wadman, S., Hufnagle, W.O., Folger, K.R., Bayer, A.S., and Stover C.K. (1998). Staphylococcus aureus genetic loci impacting growth and survival in multiple infection environments. Mol. Microbiol. 30, 393-404.

Drapeau, G.R., Boily, Y., and Houmard, J. (1972). Purification and properties of an extracellular protease of Staphylococcus aureus. J. Biol. Chem. 247, 6720-6726.

Drapeau, G.R. (1978). Role of a metalloprotease in activation of the precursor of staphylococcal protease. J. Bacteriol. 136, 607-613.

Dubin, G., Chmiel, D., Mak, P., Rakwalska, M., Rzychon, M., and Dubin, A. (2001). Molecular cloning and biochemical characterization of proteases from Staphylococcus epidermidis. Biol. Chem. 382, 1575-1582.

Fidalgo, S., Vázquez, F., Mendoza, M.C., Pérez, F., and Méndez, F.J. (1990). Bacteremia due to Staphylococcus epidermidis: microbiologic, epidemiologic, clinical, and prognostic features. Rev. Infect. Dis. 12, 520-528.

Fikes, J.D., Barkocy-Gallagher, G.A., Klapper, D.G., and Bassford, Jr. P.J. (1990). Maturation of Escherichia coli maltose-binding protein by signal peptidase I in vivo. J. Biol. Chem. 265, 3417-3423.

Fontana, A. (1988). Structure and stability of thermophilic enzymes. Studies on thermolysin. Biophys. Chem. 29. 181-193.

Gill, S.R., Fouts, D.E., Archer, G.L., Mongodin, E.F., DeBoy, R.T., Ravel, J., Paulsen, I.T., Kolonay, J.F., Brinkac, L., Beanan, M., Dodson, R.J., Daugherty, S.C., Madupu, R., Angiuoli, S.V., Durkin, A.S., Haft, D.H., Vamathevan, J., Khouri, H., Utterback, T., Lee, C., Dimitrov, G., Jiang, L., Qin, H., Weidman, J., Tran, K., Kang, K., Hance, I.R., Nelson, K.E., and Fraser, C.M. (2005). Insights on evolution of virulence and resistance from the complete genome analysis of an early methicillin-resistant Staphylococcus aureus strain and a biofilm-producing methicillin-resistant Staphylococcus epidermidis 
strain. J. Bacteriol. 187, 2426-2438.

Huebner, J., and Goldmann, D.A. (1999). Coagulase-negative staphylococci: role as pathogens. Annu. Rev. Med. 50, 223-236.

Ikeda, Y., Ohara-Nemoto, Y., Kimura, S., Ishibashi, K., and Kikuchi, K. (2004). PCR-based identification of Staphylococcus epidermidis targeting gseA encoding the glutamic- acid-specific protease. Can. J. Microbiol. 50, 493-498.

Kakudo, S., Kikuchi, N., Kitadokoro, K., Fujiwara, T., Nakamura, E., Okamoto, H., Shin, M., Tamaki, M., Teraoka, H., Tsuzuki, H., and Yoshida, N. (1992). Purification, characterization, cloning, and expression of a glutamic acid-specific protease from Bacillus licheniformis ATCC 14580. J. Biol. Chem. 267, 23782-23788.

Kawalec, M., Potempa, J., Moon, J.L., Travis, J., and Murray, B.E. (2005). Molecular diversity of a putative virulence factor: Purification and characterization of isoforms of an extracellular serine glutamyl endopeptidase of Enterococcus faecalis with different enzymatic activities. J. Bacteriol. 187, 266-275.

Kitadokoro, K., Nakamura, E., Tamaki, M., Horii, T., Okamoto, H., Shin, M., Sato, T., Fujiwara, T., Tsuzuki, H., Yoshida, N., and Teraoka, H. (1993). Purification, characterization, and molecular cloning of an acidic amino acid-specific proteinase from Streptomyces fradiae ATCC 14544. Biochim. Biophys. Acta 1163, 149-157.

Marie-Claire, C., Ruffet, E., Beaumont, A., and Roques, B.P. (1999). The prosequence of thermolysin acts as an intramolecular chaperone when expressed in trans with the mature sequence in Escherichia coli. J. Mol. Biol. 285, 1911-1915.

Moon, J.L., Banbula, A., Oleksy, A., Mayo, J.A., and Travis, J. (2001) Isolation and characterization of a highly specific serine endopeptidase from an oral strain of Staphylococcus epidermidis. Biol. Chem. 382, 1095-1099.

Nickerson, N. N., Prasad, L., Jacob, L., Delbaere, L.T., and McGavin M. J. (2007) Activation of the SspA serine protease zymogen of Staphylococcus aureus proceeds through unique variations of a trypsionogen-like mechanism and is dependent on both autocatalytic and metalloprotease-specific processing. J. Biol. Chem. 282, 34129-34138.

Nemoto, T.K., Fukuma, Y., Yamada, S., Kobayakawa, T., Ono, T., and Ohara-Nemoto, Y. 
(2004). The region adjacent to the highly immunogenic site and shielded by the middle domain is responsible for self-oligomerization/client binding of the HSP90 molecular chaperone. Biochemistry 43, 7628-7636.

Neurath, H., and Walsh, K.A. (1976). Role of proteolytic enzymes in biological regulation (A review). Proc. Natl. Acad. Sci. USA 73, 3825-3832.

O'Donohue, M.J., and Beaumont, A. (1996). The roles of the prosequence of thermolysin in enzyme inhibition and folding in vitro. J. Biol. Chem. 271, 26477-26481.

Ohara-Nemoto, Y., Ikeda, Y., Kobayashi, M., Sasaki, M., Tajika, S., and Kimura, S. (2002). Characterization and molecular cloning of a glutamyl endopeptidase from Staphylococcus epidermidis. Microb. Pathog. 33, 33-41.

Oleksy, A., Golonka, E., Bańbuła, A., Szmyd, G., Moon, J., Kubica, M., Greenbaum, D., Bogyo, M., Foster, T.J., Travis, J., and Potempa, J. (2004). Growth phase-dependent production of a cell wall-associated elastinolytic cysteine proteinase by Staphylococcus epidermidis. Biol. Chem. 385, 525-535.

Patrick, C.C. (1990). Coagulase-negative staphylococci: pathogens with increasing clinical significance. J. Pediatr. 116, 497-507.

Perlman, D., and Halvorson, H.O. (1983). A putative signal peptidase recognition site and sequence in eukaryotic and prokaryotic signal peptides. J. Mol. Biol. 167, 391-409.

Popowicz, G.M., Dubin, G., Stec-Niemczyk, J., Czarny, A., Dubin, A., Potempa, J., and Holak, T.A. (2006). Functional and structural characterization of Spl proteases from Staphylococcus aureus. J. Mol. Biol. 358, 270-279.

Prasad, L., Leduc, Y., Hayakawa, K., and Delbaere, L.T.J. (2004). The structure of a universally employed enzyme: V8 protease from Staphylococcus aureus. Acta Cryst. D60, 256-259.

Rice, K., Peralta, R., Bast, D., de Azavedo, J., and McGavin, M.J. (2001). Description of staphylococcus serine protease (ssp) operon in Staphylococcus aureus and nonpolar inactivation of sspA-encoded serine protease. Infect. Immun. 69, 159-169.

Sabat, A., Kosowska, K., Poulsen, K., Kasprowicz, A., Sekowska, A., van Den Burg, B., Travis, J., and Potempa, J. (2000). Two allelic forms of the aureolysin gene (aur) within Staphylococcus aureus. Infect. Immun. 68, 973-976. 
Sasaki, M., Ohara-Nemoto, Y., Tajika, S., Kobayashi, M., Ikeda, Y., Kaneko, M., and Takagi, T. (1998). Purification and characterization of a glutamic acid-specific protease from Staphylococcus epidermidis. Jpn. J. Oral Biol. 40, 542-548.

Shaw, L., Golonka, E., Potempa, J., and Foster, S.J. (2004). The role and regulation of the extracellular proteases of Staphylococcus aureus. Microbiology 150, 217-228.

Shevchenko, A., Jensen, O.N., Podtelejnikov, A.V., Sagliocco, F., Wilm, M., Vorm, O., Mortensen, P., Shevchenko, A., Boucherie, H., and Mann, M. (1996). Linking genome and proteome by mass spectrometry: Large-scale identification of yeast proteins from two dimensional gels. Proc. Natl. Acad. Sci. USA 93, 14440-14445.

Sabat, A., Kosowska, K., Poulsen, K., Kasprowicz, A., Sekowska, A., van Den Burg, B., Travis, J., and Potempa, J. (2000). Two allelic forms of the aureolysisn gene (aur) within Staphylococcus aureus. Infect. Immun. 68, 973-976.

Stennicke, H.R., and Breddam, K. (1998). Glutamyl endopeptidase I. In: Handbook of Proteolytic Enzymes. A.J. Barrett, N.D. Rawlings and F.F. Woessne Jr., eds. (San Diego, California: Academic Press), pp. 1448-1451.

Subbian, E., Yabuta, Y., and Shinde, U.P. (2005). Folding pathway mediated by an intramolecular chaperone: intrinsically unstructured propeptide modulates stochastic activation of subtilisin. J. Mol. Biol. 347, 367-383.

Suzuki, Y., Yabuta, M., and Ohsuye, K. (1994). Cloning and expression of the gene encoding the glutamic acid-specific protease from Streptomyces griseus ATCC10137. Gene 150, 149-151.

Teufel, P., and Götz, F. (1993). Characterization of an extracellular metalloprotease with elastase activity from Staphylococcus epidermidis. J. Bacteriol. 175, 4218-4224.

Varadi, D.P., and Saqueton, A.C. (1968). Elastase from Staphylococcus epidermidis. Nature 218, 468-470.

Yabuta, M., Ochi, N., and Ohsuye, K. (1995). Hyperproduction of a recombinant fusion protein of Staphylococcus aureus V8 protease in Escherichia coli and its processing by OmpT protease to release an active V8 protease derivative. Appl. Microbiol. Biotechnol. 44, 118-125.

Zhang, Y.Q., Ren, S.X., Li, H.L., Wang, Y.X., Fu, G., Yang, J., Qin, Z.Q., Miao, Y.G., 
Wang, W.Y., Chen, R.S., Shen, Y., Chen, Z., Yuan, Z.H., Zhao, G.P., Qu, D., Danchin, A., and Wen, Y.M. (2003). Genome-based analysis of virulence genes in a non-biofilm-forming Staphylococcus epidermidis strain (ATCC 12228). Mol. Microbiol. 49, 1577-1593. 
Table 1 N-terminal sequences and processing sites of native and recombinant GluSE.

\begin{tabular}{|c|c|c|c|c|c|c|}
\hline GluSE & $\begin{array}{l}\text { Molecular } \\
\text { weight }(\mathrm{kDa})\end{array}$ & $\begin{array}{l}\text { Detected amino acids } \\
\text { by sequencing }\end{array}$ & $\begin{array}{l}\text { Deduced sequence and } \\
\text { cleavage site }\end{array}$ & $\begin{array}{l}\text { Predicted } \\
\text { structure }\end{array}$ & $\begin{array}{c}\text { Calculated } \\
\text { molecular mass }{ }^{\mathrm{a}}\end{array}$ & $\begin{array}{l}\text { Calculated } \\
\mathrm{pI}^{\mathrm{a}}\end{array}$ \\
\hline \multirow[t]{4}{*}{ Native } & $\begin{array}{l}32 \\
32 \text { (cell wall) }{ }^{b}\end{array}$ & $\begin{array}{l}\text { KTDTESHNHS } \\
\text { KTDTE }\end{array}$ & A $\mid K_{28}$ TDTESHNHS & $\mathrm{K}_{28}-\mathrm{Gln} 282$ & 27858 & 6.21 \\
\hline & 30 & SHNHSSLGTE & $\mathrm{E} \mid \mathrm{S}_{33} \mathrm{HNHSSLGTE}$ & $\mathrm{S}_{33}-\mathrm{Gln}_{282}$ & 27283 & 6.39 \\
\hline & 29 & INSSSHNIKP & $\mathrm{D} \mid \mathrm{I}_{49} \mathrm{NSSSHNIKP}$ & $\mathrm{I}_{49}-\mathrm{G} \ln _{282}$ & 25549 & 6.50 \\
\hline & 28 & VILPNNNRHQ & $\mathrm{S}$ |V 67 ILPNNNRHQ & $\mathrm{V}_{67}-\mathrm{Gln}_{282}$ & 23579 & 5.95 \\
\hline \multirow[t]{5}{*}{ Recombinant } & 32 & KTDTESHNHS & $\mathrm{A} \mid \mathrm{K}_{28}$ TDTESHNHS & & & \\
\hline & $30^{\mathrm{c}}$ & SHNHSSL & $\mathrm{E} \mid \mathrm{S}_{33} \mathrm{HNHSSL}$ & & & \\
\hline & & SSLGTENKNV & $\mathrm{H} \mid \mathrm{S}_{37}$ SLGTENKNV & & & \\
\hline & 29 & INSSSHNI & $\mathrm{D} \mid \mathrm{I}_{49} \mathrm{NSSSHNI}$ & & & \\
\hline & $28^{\mathrm{d}}$ & VILPNNNRH & $\mathrm{S} \mid \mathrm{V}_{67} \mathrm{ILPNNNRH}$ & & & \\
\hline
\end{tabular}

${ }^{a}$ Values were calculated by GENETYX software (GENETYX Corp., Tokyo, Japan) with the DNA sequence of GluSE (OharaNemoto et al., 2002).

${ }^{b}$ Major GluSE species in the cell wall-associated fraction.

${ }^{\mathrm{c}}$ Mixture of two polypeptides.

${ }^{\mathrm{d}}$ The species produced by thermolysin treatment. 


\section{Figure legends}

Figure 1 2D-PAGE of GluSE produced from S. epidermidis.

(A) One hundred $\mu \mathrm{g}$ of proteins of the extracellular fraction from the DM culture were separated on 2D-PAGE gels, as described in Materials and methods. The positions of 32-, 30-, 29-, and 28-kDa GluSE and 22-kDa Ecp are indicated. M represents the rainbow molecular markers. (B) The four forms of GluSE were plotted based on the calculated molecular mass and pI values (Table 1).

Figure 2 2D-PAGE of GluSE in the cell wall-associated fraction.

One hundred $\mu \mathrm{g}$ of proteins in the cell wall-associated fraction prepared from $S$. epidermidis was separated on 2D-PAGE gels and detected by (A) CBB staining and (B) immunoblotting with the anti-GluSE polyclonal antibody. The positions of 32-, 30-, 29-, and 28-kDa GluSE are indicated. M, molecular markers.

Figure 3 Heterologous expression and spontaneous conversion of GluSE.

The purified fractions of rGluSE $(10 \mu \mathrm{g} / 30 \mu \mathrm{l})$ were allowed to stand at $25^{\circ} \mathrm{C}$ for $0,1,2$, 3, 5, and 7 days. (A) Aliquots $(1.8 \mu \mathrm{g})$ were separated on SDS-PAGE gels. Apparent molecular weights of the bands are indicated on the left. (B) The proteolytic activity of the samples $(1 \mu \mathrm{g})$ toward Z-LLE-MCA was measured as described in Materials and methods. Values are shown as the mean of 2 samples. The activity of the extracellular proteins (1 $\mu \mathrm{g})$ in the DM culture was measured as a control (DM).

Figure 4 In vitro processing of rGluSE by thermolysin.

$\operatorname{rGluSE}(50 \mu \mathrm{g} / 60 \mu \mathrm{l})$ was incubated without protease at $0^{\circ} \mathrm{C}$ (lane 1$)$ and $37^{\circ} \mathrm{C}$ (lane 2 ), or with $0.3 \mathrm{ng}$ (lane 3), $1 \mathrm{ng}$ (lane 4), $3 \mathrm{ng}$ (lane 5), $10 \mathrm{ng}$ (lane 6), $30 \mathrm{ng}$ (lane 7), $0.1 \mu \mathrm{g}$ (lane 8), and $0.3 \mu \mathrm{g}$ (lane 9) of thermolysin (molar ratio $180000: 1$ to $180: 1$ ) at $37^{\circ} \mathrm{C}$ for 4 
h. As a control, thermolysin $(0.3 \mu \mathrm{g})$ was incubated without GluSE (lane 10). An extracellular fraction of the DM culture is presented in lane 11, and an equal mixture of lanes 1 and 9 is shown in lane 12. Thermolysin-treated samples were separated on SDS-PAGE gels and an aliquot of (A) $1.5 \mu \mathrm{g}$ was subjected for CBB staining and (B) that of $3 \mu \mathrm{g}$ was subjected to zymography. (C) Proteolytic activity of the samples (1 $\mu \mathrm{g})$ was measured. Columns 1-11 are identical to those of lanes 1-11 in panels A and B. Values are shown as the mean $\pm \mathrm{SD}(\mathrm{n}=3)$.

Figure 5 Analysis of the autoprocessing of rGluSE.

(A) Lane 1, rGluSE; lanes 2-7, rGluSE incubated at 0.003 (lane 2), 0.01 (lane 3), 0.03 (lane 4), 0.1 (lane 5), 0.3 (lane 6), and $1 \mu \mathrm{g} / \mathrm{ml}$ (lane 7) for $72 \mathrm{~h}$ at $37^{\circ} \mathrm{C}$; lane $8, \mathrm{rGluSE}$ treated with thermolysin. Incubation was carried out in $20 \mathrm{mM}$ Tris- $\mathrm{HCl}, \mathrm{pH} 8.0,5 \mathrm{mM}$ EDTA and $0.05 \% \mathrm{NaN}_{3}$. Aliquots (60 ng) were detected by immunoblotting. (B) rGluSE (wt) (lanes 1 and 2) and rGluSE S235A (mut) (lanes 3 and 4) (10 $\mu \mathrm{g} / 0.1 \mathrm{ml}$ ) were incubated without protease at $0^{\circ} \mathrm{C}$ or with thermolysin $(0.3 \mu \mathrm{g})$ at $37^{\circ} \mathrm{C}$ for $4 \mathrm{~h}$. Aliquots $(0.5 \mu \mathrm{g})$ were subjected to SDS-PAGE. Thermolysin alone was loaded (lane 5). M, molecular markers. (C) The proteolytic activity of aliquots $(0.25 \mu \mathrm{g})$ was measured. Columns 1-5 are identical to those of lanes 1-5 in panel B.

Figure 6 Effect of N-terminal truncation on the processing and the proteolytic activity of GluSE.

(A) Truncated rGluSEs expressed in E. coli are schematically illustrated with the pre-segment $\left(\mathrm{M}_{1}-\mathrm{A}_{27}\right)$, pro-segment $\left(\mathrm{K}_{28}-\mathrm{S}_{66}\right)$, mature peptide $\left(\mathrm{V}_{67}-\mathrm{Q}_{282}\right)$, and additional MGGS at the N-terminus and GSRSHHHHHH at the C-terminus (filled boxes). Purified rGluSEs $(10 \mu \mathrm{g})$ were treated with thermolysin $(0.3 \mu \mathrm{g}$, molar ratio 36:1). rGluSEs $(0.5 \mu \mathrm{g})$ with $(+)$ and without $(-)$ the thermolysin-treatment were separated on SDS-PAGE, and (C) their proteolytic activity $(0.25 \mu \mathrm{g})$ toward LLE-MCA was measured. Data are the means $\pm \operatorname{SD}(n=3)$ from one of the three independent experiments. (D) Ten $\mu \mathrm{g}$ 
of rGluSE (open circles), rGluSE Ile 56 (closed circles), and rGluSE Ser 66 (triangles) were incubated at $37^{\circ} \mathrm{C}$ with thermolysin at ratios from $10800: 1$ to $3.6: 1$. After $4 \mathrm{~h}$, the proteolytic activity was measured. Data are the means $\pm \operatorname{SD}(n=3)$.

Figure 7 N-terminal amino acid sequence and processing sites of GluSE.

The amino acid sequence around the preproregion $\left(\mathrm{M}_{1}-\mathrm{S}_{66}\right)$ of GluSE is shown. The sites putatively processed by $S$. epidermidis signal peptidase and metalloprotease are marked with arrows. The auto-proteolytic sites are marked with arrowheads. The proposed signal sequence is indicated by asterisks, and eleven residues $\left(\mathrm{I}_{56}-\mathrm{S}_{66}\right)$, which is able to support the efficient thermolysin processing are written in bold. 
Figure 1

A

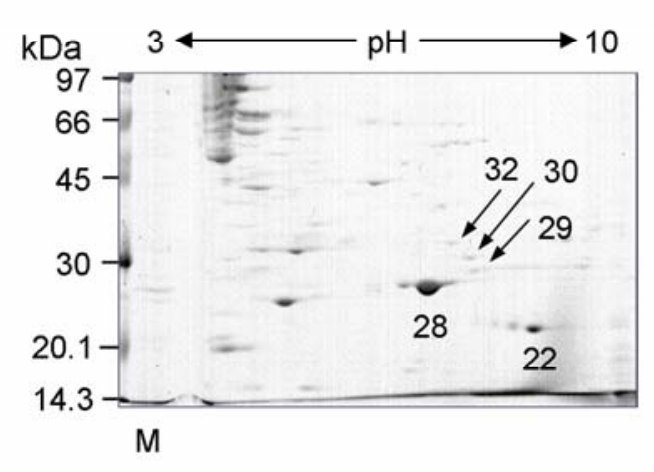

B

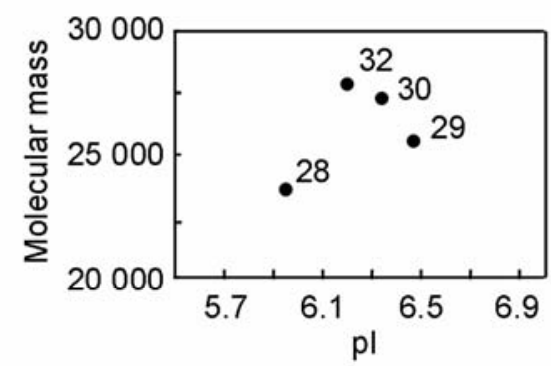

Ohara-Nemoto $Y$ et al. 
Figure 2

A

B

$\mathrm{kDa}$
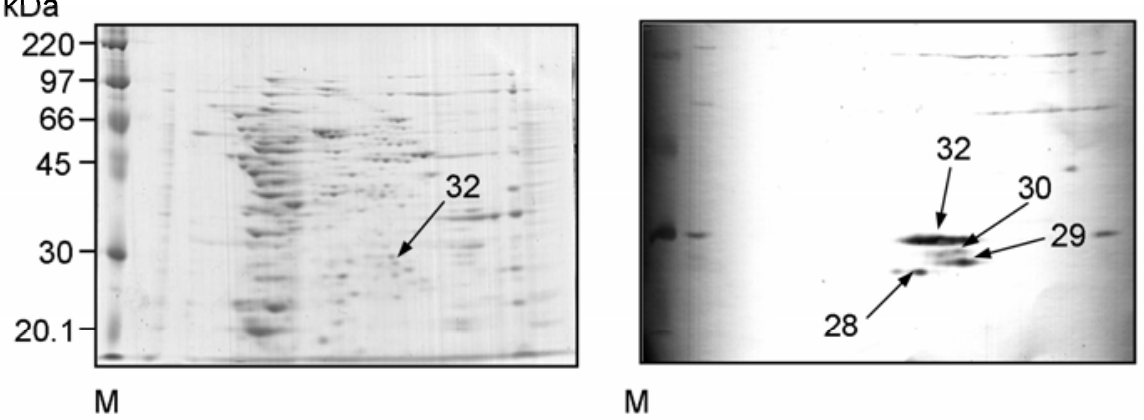

Ohara-Nemoto $Y$ et al. 
Figure 3

A

B
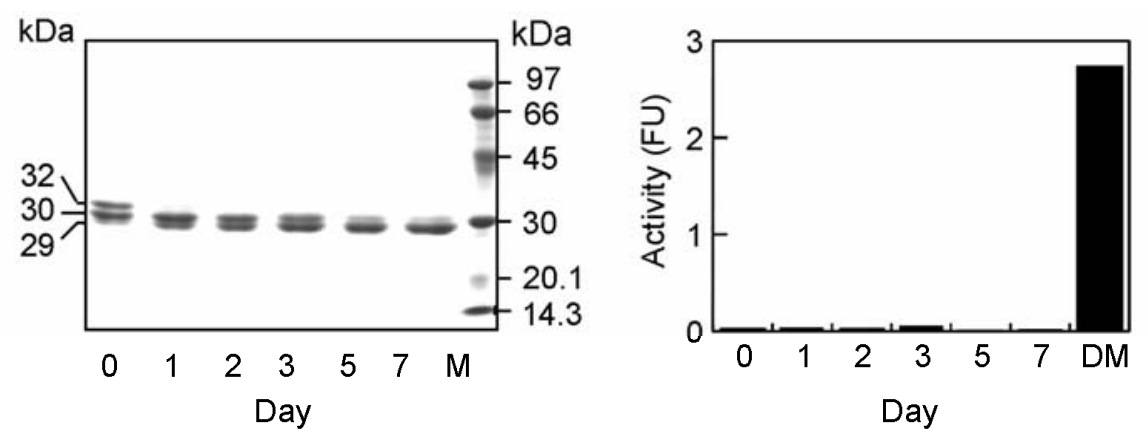

Ohara-Nemoto $Y$ et al. 
Figure 4

A

C
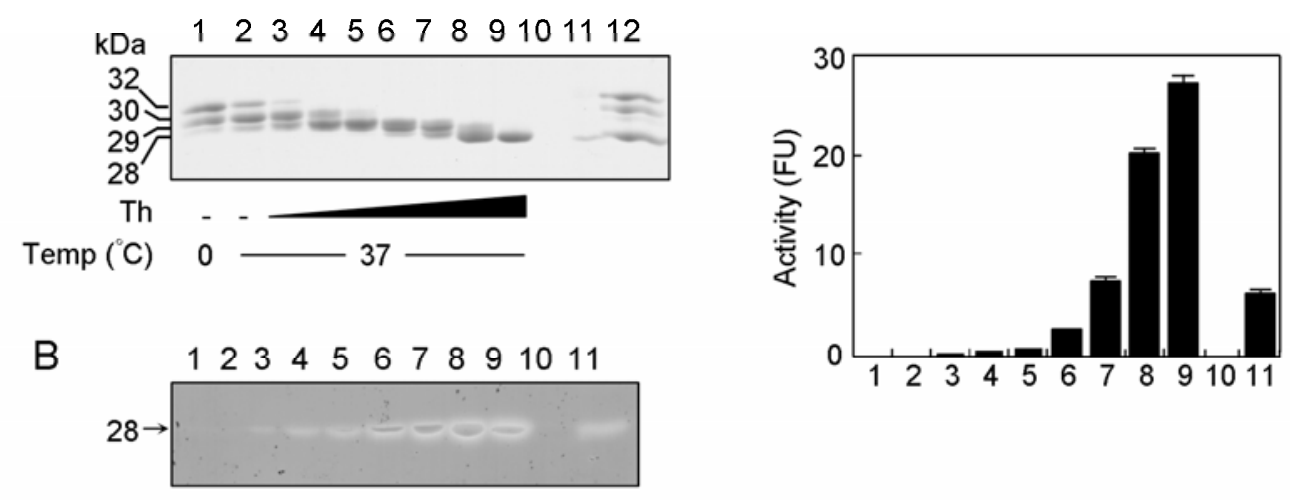

Ohara-Nemoto $Y$ et al. 
Figure 5

A

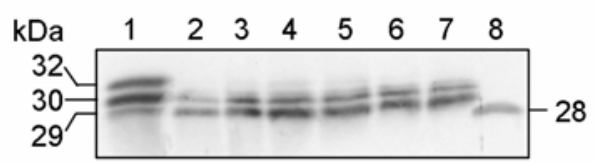

B

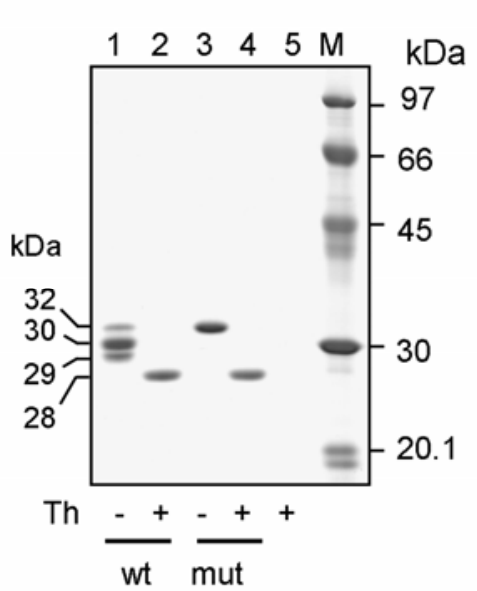

C

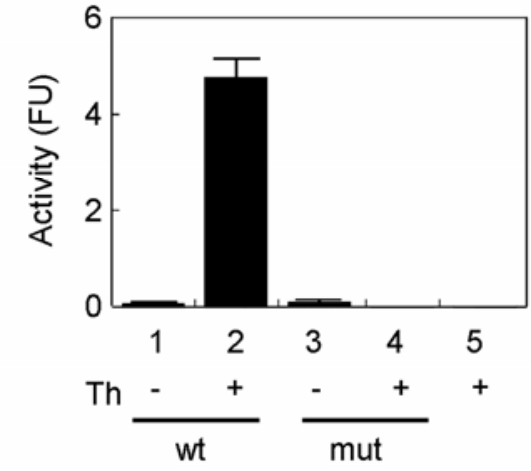

Ohara-Nemoto $Y$ et al. 
Figure 6

A

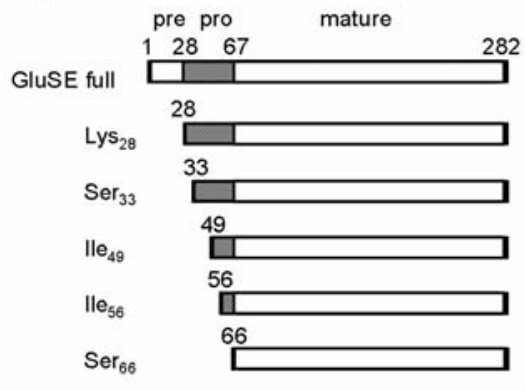

C

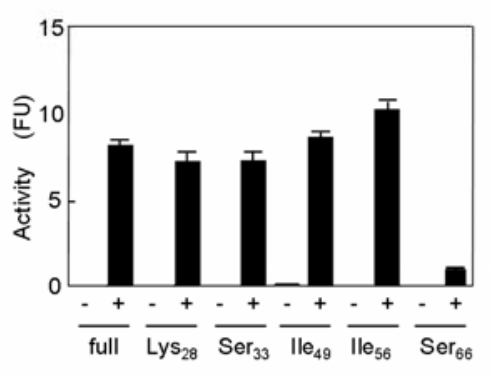

B

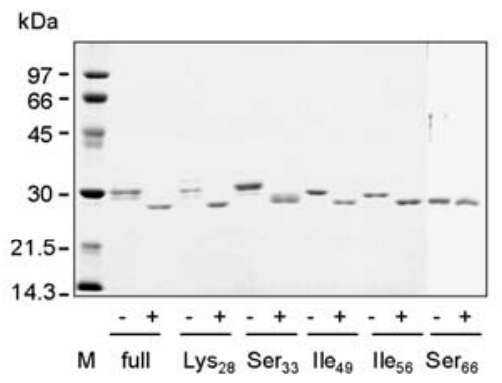

D

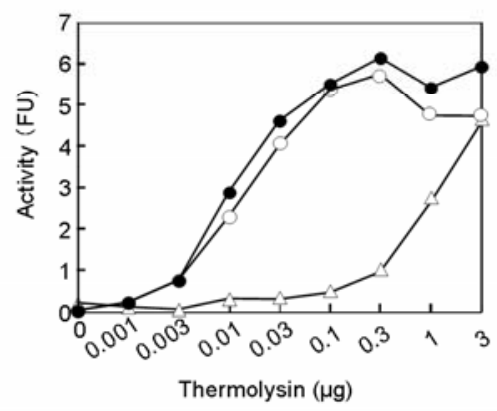

Ohara-Nemoto $Y$ et al. 
Figure 7

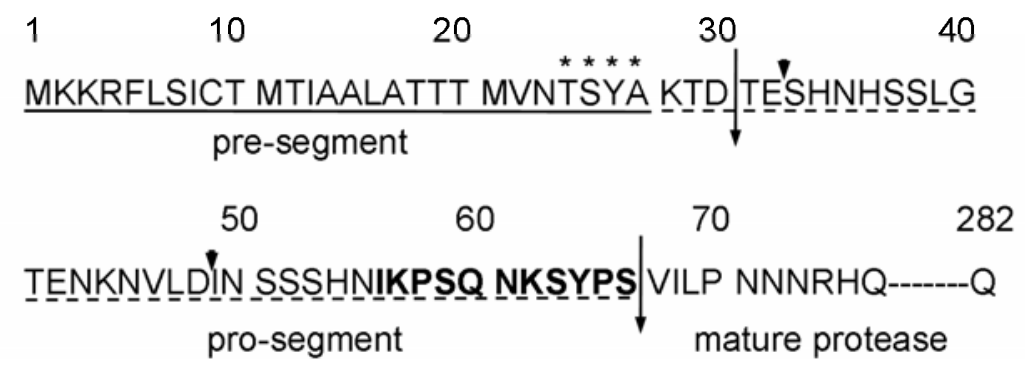

Ohara-Nemoto $Y$ et al. 